\title{
Loss of estrogen-mediated immunoprotection underlies female gender bias in experimental Crohn's-like ileitis
}

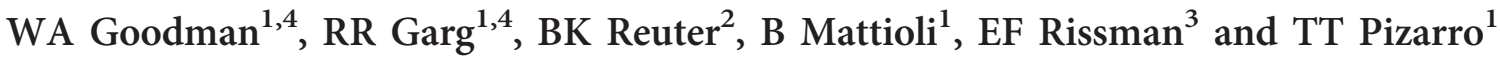

The incidence and severity of Crohn's disease (CD) are increased in female patients. Using SAMP1/YitFc (SAMP) mice, a spontaneous model of chronic intestinal inflammation that displays histologic and pathogenic similarities to human CD, we investigated the potential mechanism(s) contributing to sex differences observed in CD. Similar to gender differences observed in CD patients, SAMP female (SAMP-F) mice displayed an earlier onset and more severe ileitis compared with SAMP male (SAMP-M) mice. Furthermore, T-regulatory cells (Tregs) from gut-associated lymphoid tissue (GALT) of SAMP-F mice were reduced in frequency and impaired in their in vitro and in vivo suppressive functions compared with that of SAMP-M mice. Given the interaction between sex hormones and Treg function, we investigated the possible role of estrogen (E2) in SAMP ileitis. SAMP-M mice responded to exogenous E2 administration by expanding Treg frequency and reducing ileal inflammation, whereas SAMP-F mice were resistant. Conventional T cells and Tregs responded differentially to estrogen signaling, leading to distinct immunoprotective effects mediated by distinct estrogen receptor (ER) isoforms. These mechanisms were impaired in T cells from SAMP-F mice. Thus, hormone signaling influences the expansion and function of GALT Tregs in an ER-dependent manner and contributes to gender-based differences in experimental CD.

\section{INTRODUCTION}

Autoimmune diseases collectively affect $>20$ million people, with a disproportionate occurrence in the female population. ${ }^{1,2}$ The extent of gender bias is disease specific, reaching as high as 50:1 (female to male ratio) in Hashimoto's thyroiditis. ${ }^{3}$ Gender disparity has been reported for the occurrence of inflammatory bowel disease (IBD), particularly for Crohn's disease (CD), with a modestly increased incidence in female patients compared with male patients. ${ }^{4,5}$ In addition to a bias in favor of adult female patients, emerging evidence indicates that the severity of intestinal inflammation greatly differs between sexes, such that female CD patients are likely to experience more severe disease manifestations compared with male patients. ${ }^{6}$ Changes in clinical symptoms, both relapsing and remitting, are often associated with hormonal surges during puberty, pregnancy, and the post-partum period. ${ }^{7}$
Several factors contribute to the pathogenesis of IBD. Although the precise etiology is currently unknown, it is generally accepted that IBD results from a dysregulated immune response to exogenous factors, such as pathogenassociated molecular patterns (e.g., gut microflora), in genetically predisposed individuals. Genome-wide association studies in IBD cohorts have identified several candidate susceptibility loci, including the HLA and TNF regions of chromosome 6 , the NOD region of chromosome 16, and additional loci on chromosome X (ChrX), including FOXP3. ${ }^{8}$ These regions have been associated with a genetic predisposition to IBD, and high-frequency haplotypes on ChrX have recently been shown to be associated with female IBD patients. ${ }^{9}$ Interestingly, ChrX contains susceptibility loci linked to several other autoimmune diseases, including Wiskott-Aldrich syndrome and an associated colitis phenotype in both humans and

\footnotetext{
${ }^{1}$ Department of Pathology, Case Western Reserve University School of Medicine, Cleveland, Ohio, USA. ${ }^{2}$ Centre of Excellence for Gastrointestinal Inflammation and Immunity Research, University of Alberta, Edmonton, Alberta, Canada and ${ }^{3}$ Department of Biochemistry and Molecular Genetics, University of Virginia Health System, Charlottesville, Virginia, USA. Correspondence: TT Pizarro (theresa.pizarro@case.edu)

${ }^{4}$ The first two authors contributed equally to this work.
} 
mice. ${ }^{10}$ Despite the linkage associations on $\mathrm{ChrX}$, little is known regarding the specific candidate genes involved in IBD sex differences, or the mechanisms by which the mucosal immune system may interact with sex hormones and their receptors.

E2 signaling is generally immunoprotective, and despite their increased susceptibility to autoimmune disorders, female patients have been reported to exhibit more robust immune responses against infectious agents. ${ }^{8}$ Although E2 signaling may lead to divergent effects in different disease settings, ${ }^{11,12}$ antiinflammatory effects of E2 and estrogen receptor (ER) agonists in rodent models of Th1-mediated colitis have been described, ${ }^{13,14}$ supporting a protective role for E2 in chronic intestinal inflammation. Estrogen exerts its regulatory effects through two nuclear receptors, ER- $\alpha$ and ER- $\beta$, which initiate intracellular signaling, activate transcription of ER-dependent genes, and serve as co-factors for other transcriptional elements. ${ }^{15}$ Although ERs are expressed by a variety of immune cells within the gastrointestinal mucosa, including lymphocytes, macrophages, and dendritic cells, ${ }^{16}$ specific mechanism(s) by which estrogen-ER interactions exert their immunoprotective effects in the gut have not been fully elucidated.

The frequency and/or function of $\mathrm{CD} 4{ }^{+} \mathrm{CD} 25^{+}$Foxp $3^{+}$ T-regulatory cells (Tregs) are impaired in many human autoimmune diseases and experimental inflammatory models, including SAMP ileitis. ${ }^{17}$ Tregs have a critical role in maintaining immune tolerance to self-antigens and dampening deleterious immune responses, ${ }^{18,19}$ and are particularly important in the prevention of autoimmune gastritis and IBD. $^{20-22}$ Seminal work demonstrated that $\mathrm{CD} 4{ }^{+} \mathrm{CD} 45 \mathrm{RB}^{\text {low }}$ $\mathrm{T}$ cells, which primarily encompass a subset of $\mathrm{T}$ cells with regulatory function, have the ability to downregulate experimental colitis in recipient mice when adoptively co-transferred with $\mathrm{CD} 4{ }^{+} \mathrm{CD} 45 \mathrm{RB}^{\mathrm{hi}}$ pathogenic $\mathrm{T}$ cells. ${ }^{23}$ Importantly, adoptive transfer experiments have also shown that $\mathrm{CD} 4^{+}$ $\mathrm{CD} 25^{+}$Foxp $3^{\text {hi }}$ naturally occurring Tregs (nTregs) are able to maintain normal gut homeostasis by dampening memory effector T-cell (Teff) expansion during mucosal immune responses to bacterial infection through production of IL-10 and TGF $\beta$, and expression of functional molecules including PD1, CTLA-4, and LAG3. ${ }^{24}$

In order to mechanistically determine pathogenic factors contributing to gender disparity observed in $\mathrm{CD}$ and the potential interaction between sex hormones and Treg function, we utilized the SAMP mouse strain, a spontaneous murine model of human CD (reviewed in ${ }^{25}$ ). The ileitis phenotype in SAMP mice occurs spontaneously without chemical, genetic, or immunologic manipulation, and recapitulates the human condition for disease location (terminal ileum), discontinuous nature of inflammatory lesions, and response to standard therapies used for treating CD. Inflammation is fully developed by 10 weeks of age, with Th1-type immune responses predominating early during the inductive phase, and a mixed Th1/Th2 phenotype emerging as ileitis develops into chronic, established disease. Mesenteric lymph nodes (MLNs) of SAMP mice display increased size and cellularity compared with AKR/ J mice (AKR, control parental strain), with SAMP-derived conventional $\mathrm{CD} 4{ }^{+} \mathrm{T}$ cells capable of adoptively transferring ileitis to naïve SCID recipients. ${ }^{26} \mathrm{~A}$ global increase in Treg frequency is observed in SAMP compared with AKR MLN, although Tregs from SAMP $\left(\mathrm{CD} 4{ }^{+} \mathrm{CD} 25^{+}\right)$mice are functionally impaired in preventing colitis when adoptively co-transferred into SCID recipients with pathogenic, Treg-depleted conventional T cells (Tconvs). ${ }^{17}$ These observations have never been evaluated with regard to potential sex differences.

Herein, we report that SAMP mice, similar to Crohn's patients, display a gender bias for intestinal inflammation, with SAMP female (SAMP-F) mice showing an earlier onset and increased disease severity compared with SAMP-M mice. We confirmed these findings in $T N F^{\triangle \mathrm{ARE} /+}$ mice, a second model of chronic ileitis displaying Crohn's-like pathology. ${ }^{27}$ Tregs from SAMP-F mice display reduced Foxp3 expression and reduced suppressive function, both in vivo and in vitro. This gender disparity appears to be dependent on signaling through different ER isoforms and their downstream functional effects on Treg differentiation, including E2-mediated induction of Treg markers in naive $\mathrm{T}$ cells from SAMP-M, but not from SAMP-F mice; E2-mediated suppression of T-cell proliferation in SAMP-M, but not in -F mice; and enhancement of Treg function in SAMP-M, but not in -F mice. Taken together, our data demonstrate that estrogen signaling is immunoprotective via direct effects on dampening Tconv proliferation and inducing conversion to Tregs. These normally protective mechanisms are compromised in SAMP-F mice, leading to alterations in T-cell homeostasis. Thus, differential responses to $\mathrm{E} 2$ among male and female $\mathrm{T}$ cells likely contribute to the increased severity of intestinal inflammation observed in SAMP-F mice and female CD patients.

\section{RESULTS}

\section{Early onset and increased severity of ileitis in SAMP-F mice}

Ileal inflammation in age-matched cohorts of SAMP-M and -F mice was analyzed using a detailed time course (Figure 1a). At 5 weeks, both SAMP-M and -F mice showed minimal inflammation. By 6 weeks, corresponding to the onset of puberty, SAMP-F mice displayed increased ileal inflammation, which became more severe and disparate from SAMP-M mice up to 10 weeks of age. AKR mice had a total inflammatory score $\leq 1$ for all ileal specimens evaluated (data not shown). Both active (acute) and chronic inflammation were significantly increased in SAMP-F mice compared with SAMP-M mice from 7 to 10 weeks of age, with villous distortion significantly elevated in SAMP-F mice at 7 and 10 weeks (Figure 1b). At 6 weeks of age, SAMP-F mice (Figure 1c, left panel) showed histologic features of epithelial crypt hypertrophy and villous blunting, dense inflammatory infiltrates throughout the villi and submucosa, and Paneth and goblet cell hyperplasia compared with age- and sex-matched SAMP-M and AKR mice (Figure 1c, middle and right panels). These data strongly show an earlier onset of ileitis with increased disease severity in SAMP-F vs. -M mice, similar to that reported in CD patients. 


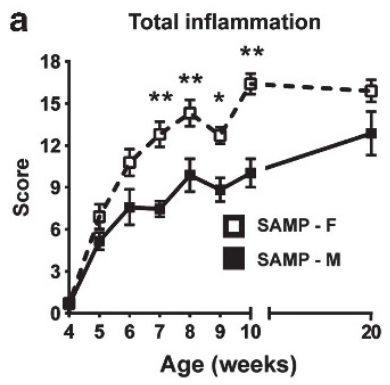

b
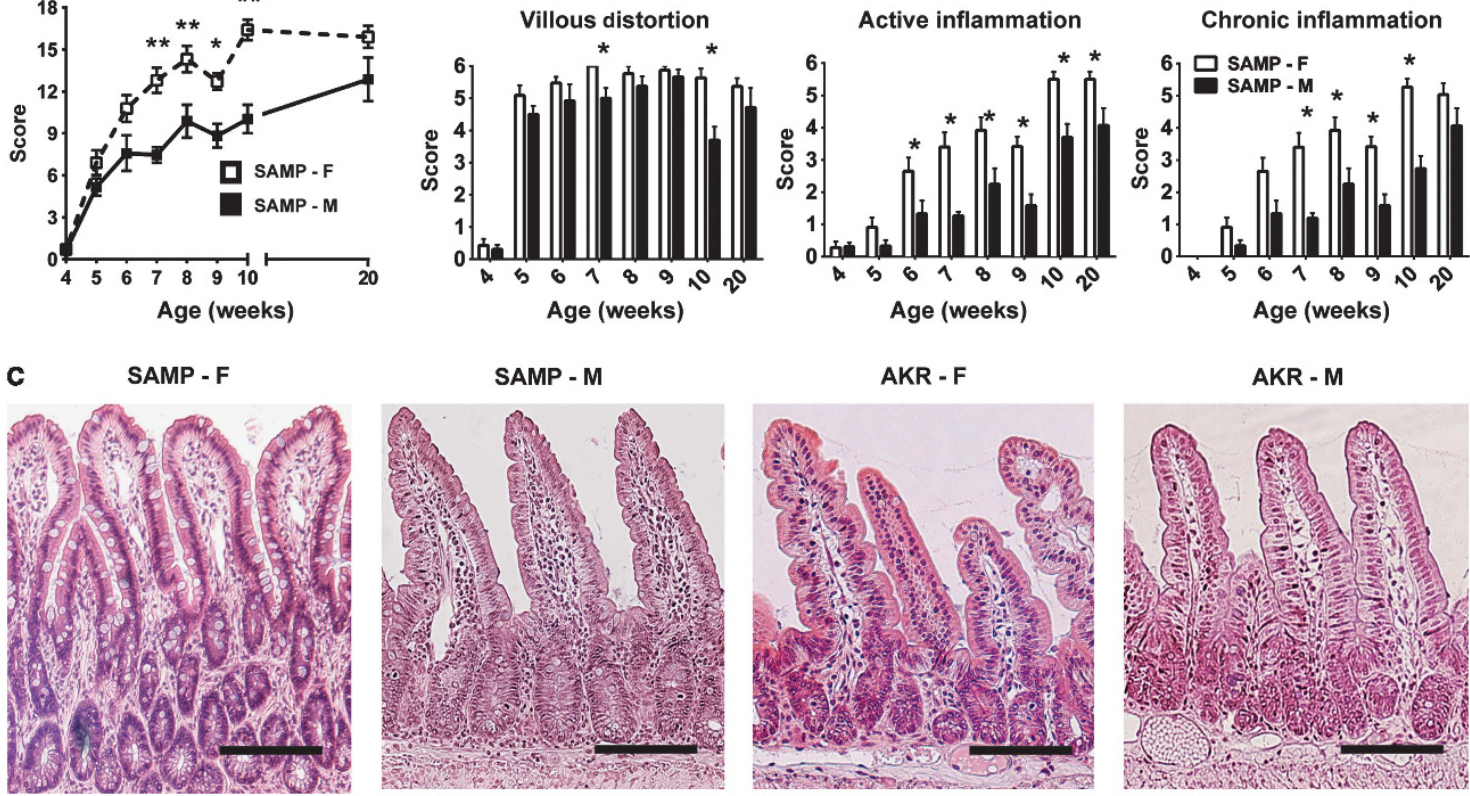

Figure 1 SAMP-F mice exhibit early, severe ileitis compared with SAMP-M mice. (a) Time course of ileitis in age-matched cohorts of SAMP-F and $-\mathrm{M}$ mice. Composite inflammatory scores are represented as mean $\pm \mathrm{SEM}\left({ }^{\star} P<0.05,{ }^{* *} P<0.01, n=12 /\right.$ group). (b) Time course of histologic indices representing active inflammation, chronic inflammation, and villous distortion expressed as mean \pm s.e.m. ( ${ }^{\star} P \leq 0.05, n=12 /$ group). (c) Representative photomicrographs of H\&E stained ilea ( $n=12 /$ group) from 6-week-old SAMP and AKR mice. Scale bar, $100 \mu \mathrm{m} ; \times 20+1.25$ original magnification.

\section{SAMP-F mice display impaired frequency and in vitro function of $\mathrm{CD}_{25}{ }^{+}$Foxp3 $^{+}$Tregs}

Given the increased frequency of gut-infiltrating lymphocytes in SAMP mice, we hypothesized that regulatory mechanisms, such as Treg function, may be reduced in SAMP strain leading to ileitis. To determine whether alterations in intestinal Tregs contribute to gender differences in SAMP strains, MLN cells were collected from $>10$-week-old SAMP and AKR mice and analyzed for expression of CD25 and Foxp3. SAMP-M mice showed an increased percentage of Tregs $\left(\mathrm{CD} 4{ }^{+} \mathrm{CD} 25^{+}\right.$ Foxp $3^{\text {hi }}$ ) relative to SAMP-F and AKR controls (Figure 2a). Conversely, MLN from SAMP-F mice contained an elevated percentage of $\mathrm{CD}^{+}{ }^{+} \mathrm{T}$ cells expressing CD25 that were Foxp $3^{\text {low }}$, representing memory Teff cells, reported to be pathogenic in colitis transfer models. ${ }^{28}$ Cumulative data $(n=6-14$ animals/group) show that the mean percentage of CD25 Foxp $3^{+}$cells in SAMP-F mice is reduced compared with male mice (Figure 2b).

Gender differences in experimental CD and the critical role of Tregs in this process were confirmed by observations made in the $\mathrm{TNF}^{\mathrm{ARE} /+}$ model of Crohn's-like ileitis (Supplementary Figure S1 online). These mice possess a genetic deletion of the TNF AU-rich regulatory elements, resulting in post-transcriptional TNF de-regulation and chronic TNF overproduction that ultimately leads to the development of a CD-like pathology in the ileum. ${ }^{27}$ Similar to SAMP-F mice, female $T N F^{\Delta \mathrm{ARE} /+}$ mice show increased disease severity with an associated reduction in the overall percentage and suppressive ability of gut-associated lymphoid tissue (GALT) Tregs compared with age-matched $T N F^{\Delta \mathrm{ARE} /+}$ male mice (Supplementary Figure S1). These data establish that observations regarding sex differences in experimental ileitis do not appear to be model-specific and further support the gender-dependent role of Tregs in influencing the severity of disease in CD patients.

\section{SAMP-F Tregs are dysfunctional in vivo}

Adoptive transfer of $\mathrm{CD}^{+}{ }^{+} \mathrm{CD} 45 \mathrm{RB}^{\text {hi }} \mathrm{T}$ cells to immunodeficient SCID mice results in progressive colitis. ${ }^{23}$ Importantly, when $\mathrm{CD}^{+}{ }^{+} \mathrm{CD} 45 \mathrm{~B}^{\text {low }}$ cells (enriched for Tregs) are cotransferred with the $\mathrm{RB}^{\text {hi }}$ cells, recipients are protected from colitis. ${ }^{23}$ To determine whether SAMP Tregs express genderspecific differences in suppressive function, we reconstituted SCID mice with $\mathrm{RB}^{\text {hi }} \mathrm{T}$ cells from SAMP-M mice, with or without $\mathrm{RB}^{\text {low }}$ cells from either SAMP-M or SAMP-F mice. As expected, 8 weeks post-transfer, SCIDs reconstituted with pathogenic MLN CD4 ${ }^{+} \mathrm{CD}_{45 \mathrm{RB}}{ }^{\text {hi }} \mathrm{T}$ cells from SAMP-M mice alone $\left(\mathrm{RB}^{\mathrm{hi}}\right)$ developed a colitis phenotype (diarrhea with bloody stools, accompanied by a dramatic body weight loss) (Figure 3a). SCIDs receiving co-transfer of $\mathrm{RB}^{\text {hi }} / \mathrm{RB}^{\text {low }}$ cells (both from SAMP-M mice) showed no signs of colitis and exhibited less weight loss relative to recipients receiving $\mathrm{RB}^{\mathrm{hi}}$ cells alone. Interestingly, SCIDs receiving mixed gender $\mathrm{RB}^{\mathrm{hi}}$ $\mathrm{M} / \mathrm{RB}^{\text {low }}$-F SAMP cells developed colitis with severity similar to recipients of $\mathrm{RB}^{\mathrm{hi}}$ cells alone (Figure $3 \mathbf{b}$ ). The inability of female $\mathrm{RB}^{\text {low }}$ cells to reverse colitis was not due to a decrease in the number of Tregs transferred, as comparable percentages of $\mathrm{CD} 25^{+} \mathrm{Foxp}^{+}$Tregs were found within the $\mathrm{CD} 4{ }^{+}$ $\mathrm{CD}_{45 \mathrm{RB}^{\text {low }}}$ population regardless of gender $(5.57 \pm 0.42 \%$ in SAMP-F cells vs. $5.50 \pm 0.75 \%$ in SAMP-M cells) (Figure $3 c$ ). The fluorescence-activated cell sorting (FACS)-based gating 


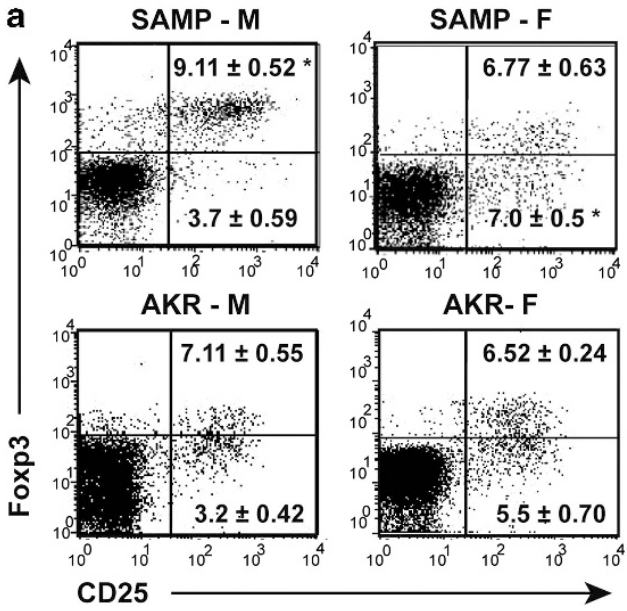

b

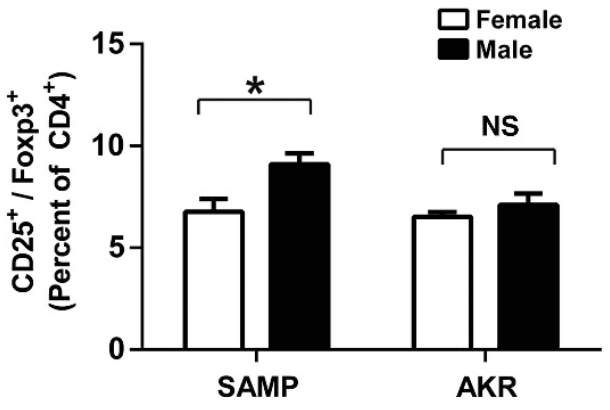

Figure 2 Treg frequency is decreased in SAMP-F mice compared with SAMP-M mice. (a) Representative FACS histograms show expression of CD25 and Foxp3 among CD4-gated lymphocytes from MLNs (mice $\geq 10$ weeks). (b) Quantification of results from a. Percentages of $\mathrm{CD}^{2} 5^{+} / \mathrm{Foxp}^{+}{ }^{+} \mathrm{T}$ cells are expressed as mean \pm s.e.m. ( ${ }^{*} P<0.01, n=8-14 /$ group $)$.
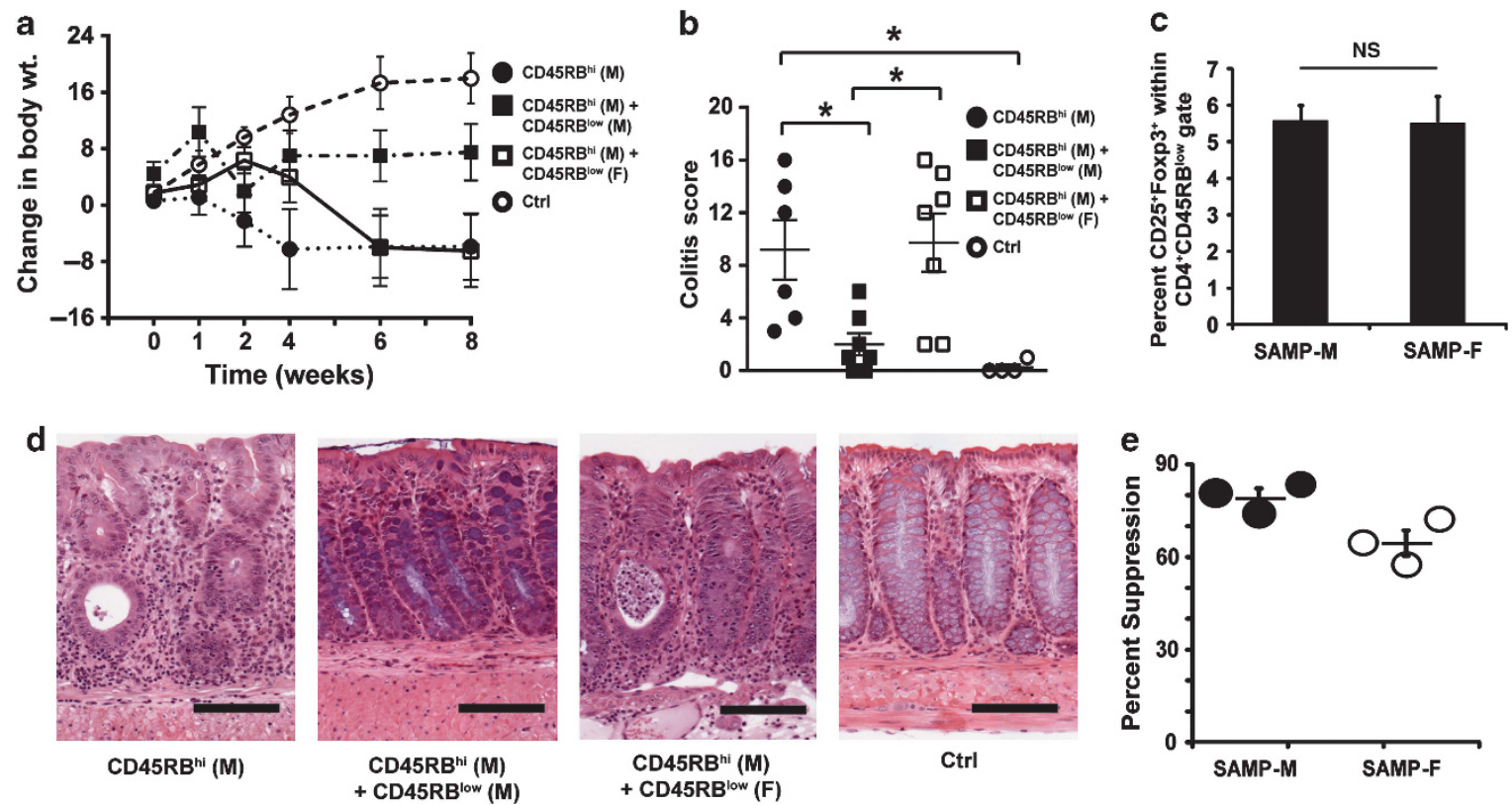

Figure 3 Tregs from SAMP-F mice are dysfunctional in vivo and in vitro. Six-week-old SCID mice were reconstituted with FACS-Sorted MLN CD45RB ${ }^{\text {hi }}$ CD4 ${ }^{+}$T cells from SAMP-M mice alone ( RB $\left.^{\text {hi }}\right)$ or co-transferred with MLN CD45RB ${ }^{\text {low }}$ CD4 ${ }^{+}$T cells from either SAMP-M ( $\mathbf{R}$ RB $\left.{ }^{\text {low }}-M\right)$ or SAMP-F mice ( $\square$ RB $\left.^{\text {low }}-F\right)$; vehicle, mock-transferred SCIDs served as controls ( $\bigcirc$ Ctrl). (a) Changes in body weight are shown in weeks post-transfer and (b) histologic evaluation of colitis is shown at 8 weeks post-transfer. Percent change in body weight and composite inflammatory scores are represented as mean \pm s.e.m. ( ${ }^{\star} P \leq 0.05, n=16$ /group). (c) Mean percentage of CD25 ${ }^{+} /$Foxp3 ${ }^{+}$cells within the RB ${ }^{\text {low }} \mathrm{T}^{\text {-cell }}$ population of SAMP-M and $-\mathrm{F}$ mice is expressed \pm s.e.m. (d) Representative photomicrographs of colon from indicated mice (scale bar, $100 \mu \mathrm{m}$; original magnification $\times 20+1.25 \mathrm{NA}$ ). (e) In vitro Treg suppression activity. CD4 ${ }^{+} \mathrm{CD} 25^{-}$Tconvs and CD4 ${ }^{+} \mathrm{CD} 25^{+}$Tregs were isolated from SAMP-M or SAMP-F mice. Tconvs were cultured alone or with a 1:1 ratio of Treg for 3 days in the presence of $\alpha C D 3 / \alpha C D 28$. Percent suppression is expressed as the percentage of Tconv proliferation that was suppressed by co-culture with Tregs. Each dot represents one experiment (three pooled mice per experiment) \pm s.e.m.

strategy for isolation of $\mathrm{CD}^{+}{ }^{+} \mathrm{CD} 45 \mathrm{RB}^{\text {low }}$ and $\mathrm{CD} 4^{+}$ CD45RB ${ }^{\text {hi }} \mathrm{T}$ cells is shown in Supplementary Figure S2.

Histologically, colon tissues from recipients of CD45RB ${ }^{\text {hi }}$ cells alone (Figure 3d, left panel) displayed significant villous and submucosal inflammation, epithelial hypertrophy, and villous blunting. Co-transfer of RB ${ }^{\text {low }}$ cells from SAMP-M, but not from SAMP-F, mice led to a reduction of inflammation and hypertrophy (Figure 3d, middle panels), whereas control (mock-transferred) mice had minimal inflammation (Figure 3d, right panel).

Colonic inflammation in recipient mice was further characterized by examining myeloperoxidase activity in local colonic tissues, as well as cytokine secretion from $\alpha \mathrm{CD} 3 /$ $\alpha \mathrm{CD} 28$-activated MLN cells 8 weeks after transfer. Myeloperoxidase, a marker of neutrophil-mediated inflammation, was elevated in colon tissues from SCID mice transferred with 
$\mathrm{CD}_{4} \mathrm{RB}^{\text {hi }}$ cells alone, compared with tissues from control mice. Co-transfer of CD45RB ${ }^{\text {low }}$ cells from SAMP-M, but not from SAMP-F, mice was able to significantly abrogate myeloperoxidase activity (Supplementary Figure S3). Similar to the effects seen in native SAMP mice, proinflammatory cytokine secretion from activated MLN cells was increased in mice with severe colitis $\left(\mathrm{RB}^{\mathrm{hi}}\right.$ alone and $R B^{\text {hi }} / \mathrm{RB}^{\text {low }}-\mathrm{F}$ recipients) compared with $R B^{\text {hi }} / \mathrm{RB}^{\text {low }}-\mathrm{M}$ recipients and control mice (Supplementary Figure S3). Secretion of Th17-associated IL-17 and IL-22 was also increased in cells from $\mathrm{RB}^{\text {hi }}$ and $\mathrm{RB}^{\text {hi }} / \mathrm{RB}^{\text {low }}-\mathrm{F}$ recipients, and correlated to colitis severity in this model. In contrast, levels of proinflammatory Th1, Th2, and Th17 cytokines were decreased, and anti-inflammatory IL-10 was increased, in activated MLN cells from $\mathrm{RB}^{\text {hi }} / \mathrm{RB}^{\text {low }}-\mathrm{M}$ recipients compared with cells from $\mathrm{RB}^{\text {hi }}$ and $\mathrm{RB}^{\text {hi }} / \mathrm{RB}^{\text {low }}$-F recipients. Interestingly, cells from $\mathrm{RB}^{\text {hi }} / \mathrm{RB}^{\text {low }}-\mathrm{M}$ recipients also expressed higher levels of IL-2, a critical growth factor for Tregs.

In addition to testing the in vivo function of Tregs using the CD45RB adoptive transfer model, we also investigated the in vitro suppressive capacity of gender-specific SAMP Tregs using CFSE suppression assays. CD $4^{+} \mathrm{CD} 25^{-}$Tconvs and $\mathrm{CD} 4{ }^{+} \mathrm{CD} 25^{+}$Tregs were isolated by FACS (Supplementary Figure S4). Tconvs were labeled with eFluor 670 (CFSE analog) and cultured with $\alpha \mathrm{CD} 3 / \alpha \mathrm{CD} 28$, with or without Tregs for 3 days. Suppression, expressed as the percentage of proliferating cells (eFluor 670 "low") inhibited by co-culture with Tregs, was calculated for male vs. female SAMP mice. We found that Tregs from SAMP-F mice were less effective at suppressing the proliferation of Tconvs than Tregs from SAMP-M mice (Figure 3e). Together, these data confirm the in vivo findings and demonstrate that Tregs from SAMP-M mice are functionally more effective than their SAMP-F counterparts.

\section{Estrogen signaling differentially affects male and female $T$ cells in SAMP ileitis}

Previous investigators have reported that estrogen (17- $\beta$-estradiol or E2) mediates conversion of conventional naïve $\mathrm{T}$ cells (CD4 ${ }^{+} \mathrm{CD} 25^{-}$Tconvs) to Tregs in wild-type mice. ${ }^{29}$ Given our observed decrease in Tregs of SAMP-F vs. -M mice, we hypothesized that SAMP-F mice may demonstrate aberrant E2-mediated conversion of Tregs. We first characterized the expression of ER isoforms $E R \alpha$ and $E R \beta$ in primary T cells from 10-week-old SAMP and AKR male and female mice. Purified Tconvs and Tregs from all four cohorts expressed detectable $\mathrm{ER} \alpha$ and $\mathrm{ER} \beta$ in nuclear protein extracts, with no significant differences detected among male and female $\mathrm{T}$ cells. A representative western blot is shown in Figure $\mathbf{4 a}$ and mean densitometric analysis is shown in Figure $\mathbf{4 b}( \pm$ s.e.m., $n=3-5$ mice/group).

To directly test the ability of naive $\mathrm{T}$ cells to acquire a Treg phenotype in response to $\mathrm{E} 2$, Tconvs $\left(\mathrm{CD} 4{ }^{+} \mathrm{CD} 25^{-}\right)$were isolated from 10-week-old AKR and SAMP male and female mice and stimulated ex vivo with DMSO/PBS (vehicle Ctrl), E2, or the ER agonists propyl pyrazole triol (PPT, specific for ER $\alpha$ ) or diarylpropionitrile (DPN, specific for $\mathrm{ER} \beta$ ). In support of the hypothesis that E2 signaling contributes to the induction of Tregs, T cells from AKR controls and SAMP-M mice showed an increase in mRNA transcripts specific for the Treg-associated molecules Foxp3, Helios, PD1, CTLA-4, and LAG3 (Figure 4c). Interestingly, T cells from SAMP-F mice did not induce Tregassociated genes as robustly as cells from SAMP-M mice.

To study the effects of E2 signaling on fully differentiated Tregs, MLN Tregs were isolated from 10-week-old SAMP-M and -F mice and stimulated ex vivo with either vehicle Ctrl, PPT, or DPN. Interestingly, only SAMP-M mice responded to ER $\beta$ signaling via enhancement of anti-inflammatory TGF $\beta$ and IL-10 and upregulation of Foxp3 (Figure 4d). Notably, and in contrast to effects observed in SAMP-M mice, cells from SAMP-F mice did not upregulate TGF $\beta$, IL-10, or Foxp3 in response to ER agonist treatment (Figure $4 \mathbf{d}$ ).

\section{Differential effect of estrogen on ileitis and Treg expansion}

To determine whether differences in physiologic levels of estrogen may be responsible for modulating disease severity, serum estrogen was measured during post-pubertal development in SAMP and AKR mice ( $>10$ weeks of age). Although circulating estrogen levels were elevated in female compared with male mice, E2 levels were comparable between female SAMP and AKR mice, as well as between male SAMP and AKR mice (Supplementary Figure S5). Together, these results indicate that physiologic estrogen levels do not likely represent an independent risk factor for sex differences observed in SAMP ileitis.

To study the in vivo effects of E2 signaling in the absence of endogenous hormonal effects, 10-week-old SAMP-M mice were gonadectomized (GDX). These "gender-neutral" GDX-SAMP mice were then treated with i.p. injections of E2, PPT, DPN, or vehicle Ctrl. Following 6 weeks of hormone treatment, MLN cells from GDX-SAMP-M mice were examined. MLN T cells from GDX-SAMP mice showed an increase in the percentage and absolute numbers of $\mathrm{CD} 4{ }^{+} \mathrm{CD} 25^{+}$Foxp $3{ }^{+} \mathrm{T}$ cells following in vivo treatment with E2 and DPN (Figure 5a and b). This was in contrast to PPT- and vehicle-treated mice, which did not show an expansion of $\mathrm{CD}_{2} 5^{+}$Foxp $3^{+}$cells. These observations suggest that in SAMP-M mice, activation of ER $\beta$-specific pathways results in conversion of GALT-derived Tregs.

Given our previous observation that DPN preferentially augments Foxp3, IL-10, and TGF $\beta$ in Tregs (Figure 4d), and in vivo evidence of DPN-mediated expansion of GALT Tregs (Figure 5a), we asked whether clinical responses to exogenous E2 were mediated through ER-dependent pathways, as both $\mathrm{ER} \beta$ and $\mathrm{ER} \alpha$ are widely distributed throughout the gastrointestinal tract and expressed in gut mucosal cells. ${ }^{30}$ Six-week in vivo treatment of GDX SAMP-M mice with E2, PPT, and DPN resulted in decreased ileitis compared with vehicle control (Figure 5c), suggesting that the immunoprotective effects of $\mathrm{E} 2$ may be mediated by diverse mechanisms to both ER isoforms, and not solely through ER $\beta$-mediated induction of Tregs.

Given our findings of decreased ileitis in E2-treated GDXSAMP-M mice, we asked whether GDX-SAMP-F mice are 

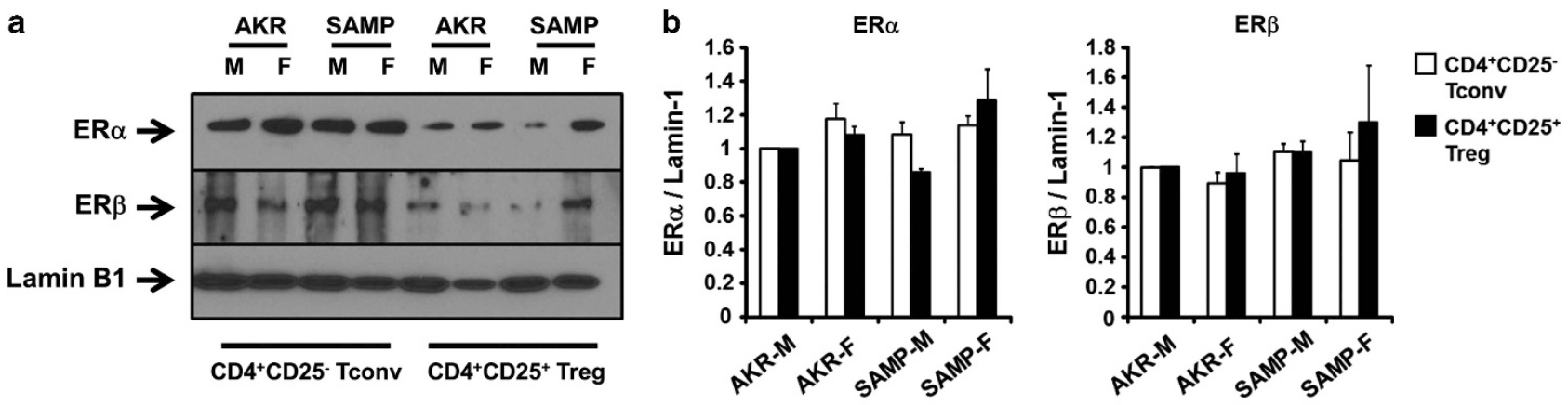

c
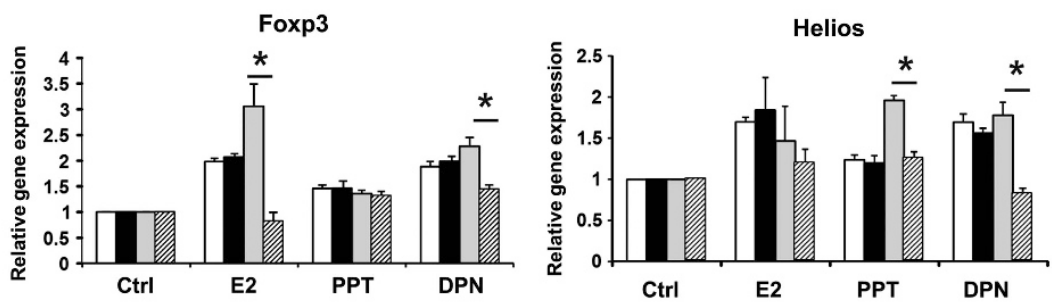

AKR-M

AKR-F

SAMP-M

SAMP-F
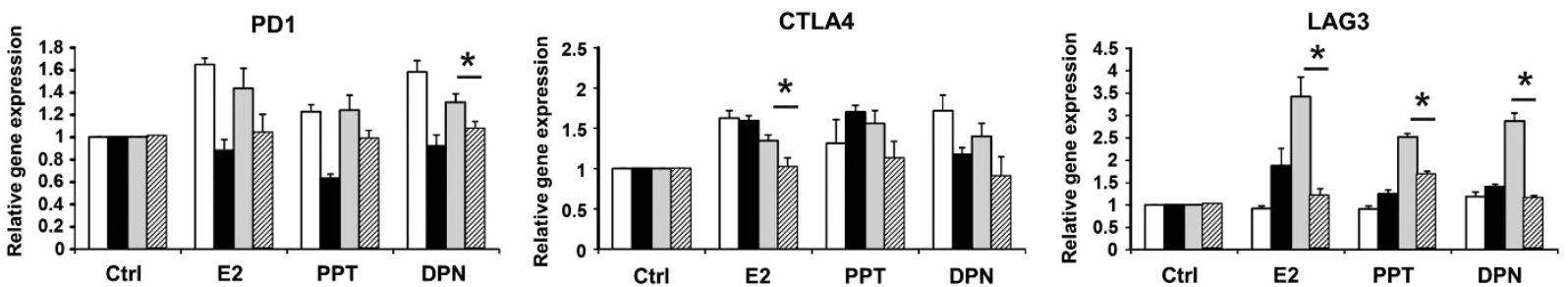

d
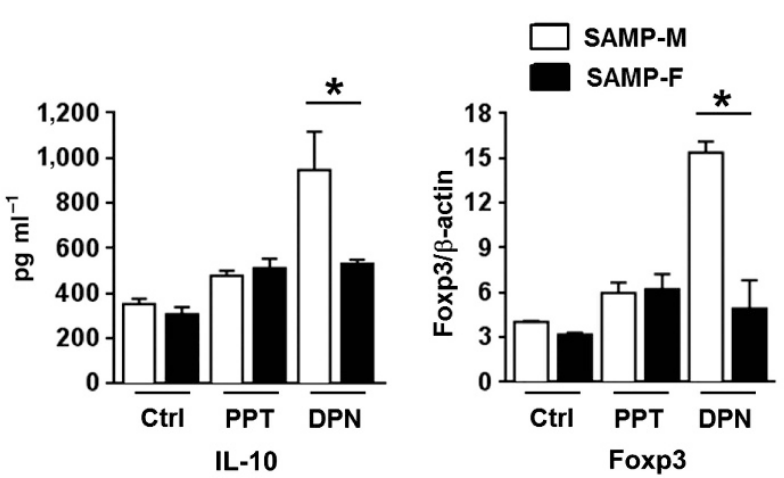

Figure 4 Estrogen signaling differentially affects Treg induction in SAMP-M vs. SAMP-F mice. (a, b) CD4 ${ }^{+}$CD25 $5^{-}$Tconvs and CD4 $^{+}$CD25 $5^{+}$Tregs were isolated from spleens of indicated mice (10 weeks of age). Nuclear protein lysates were probed for ER $\alpha$, ER $\beta$, and Lamin-1 by western blot. Representative images (a) and semi-quantitative densitometric analysis (b) are shown ( $n=3$ total experiments, 3-5 pooled mice per group). (c) $\mathrm{CD}^{+}{ }^{+} \mathrm{CD} 25^{-} \mathrm{T}$ cells were isolated from untreated, 10-week-old mice and cultured in vitro with vehicle (Ctrl), E2, PPT, or DPN (10 nm). mRNA specific for indicated genes was normalized to GAPDH and mean fold changes are expressed as mean \pm s.e.m. relative to vehicle-treated samples $\left({ }^{\star} P \leq 0.05, n=3\right.$ /group). (d) $\mathrm{CD} 4{ }^{+} \mathrm{CD} 25^{+}$Treg were isolated from MLNs of untreated, 10 -week-old mice and cultured in vitro in the presence of vehicle (Ctrl), PPT, or DPN (10 nM). Cell supernatants were analyzed for IL-10 and TGF $\beta$ protein by ELISA (left and middle) and nuclear protein lysates were probed for Foxp3 and $\beta$-actin protein by western blot (semi-quantitative densitometric analysis is shown at left). All results are expressed as mean \pm s.e.m. $\left({ }^{\star} P<0.05,{ }^{\star \star} P<0.01, n=6 /\right.$ group$)$.

similarly protected from ileitis via estrogen signaling. Tenweek-old GDX-SAMP mice were exposed to continuousreleased E2 by subcutaneously placed implants for 6 weeks as previously described. ${ }^{31}$ Interestingly, although GDX-SAMP-M mice demonstrated a partial resolution of ileitis following E2 treatment, similar to effects observed in E2-injected animals (Figure 5c), GDX-SAMP-F mice did not improve in response to estrogen (Figure 5d).

\section{SAMP-F Tregs are resistant to E2-mediated immunosuppression}

Given our observation that in vivo E2 treatment reduces ileitis selectively in SAMP-M mice, but not in SAMP-F mice (Figure 5d), we investigated the potential mechanism(s) for this differential effect. We focused our studies on the role of E2 modulation of Treg function, as we observed genderbased differences in Treg phenotype (Figure 2) and function 


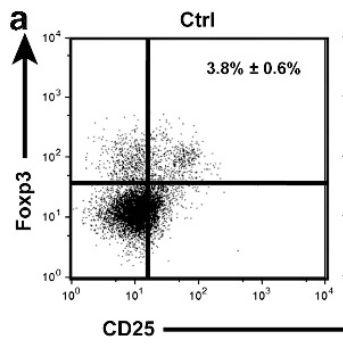

b

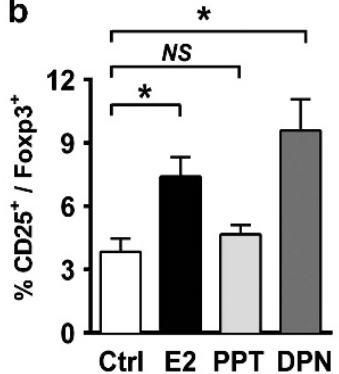

E2

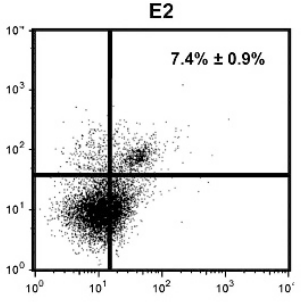

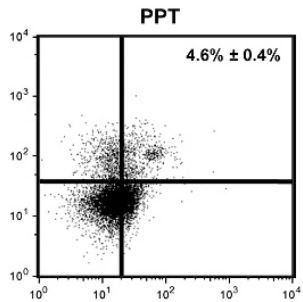

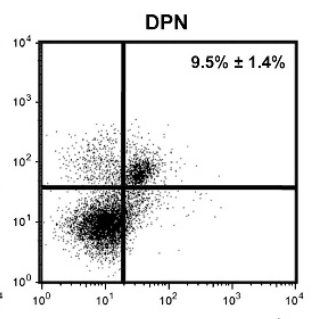

C

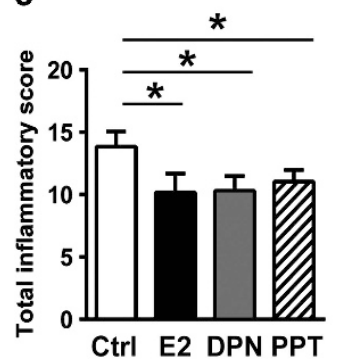

d

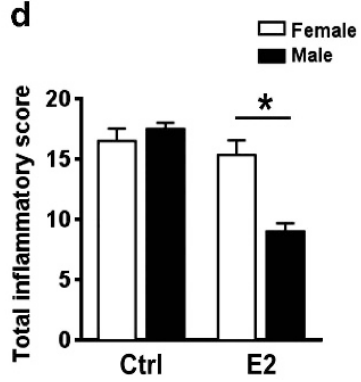

Figure 5 E2 signaling is protective against ileitis in SAMP-M mice. (a-c) Ten-week-old GDX-SAMP mice were administered vehicle (Ctrl), E2 $\left(10 \mathrm{ug} \mathrm{kg}^{-1}\right)$, PPT $\left(10 \mathrm{mg} \mathrm{kg}^{-1}\right)$, or DPN $\left(10 \mathrm{mg} \mathrm{kg}^{-1}\right)$ by i. p injection. Following 6 weeks of treatment, MLNs were harvested and cells stained for flow cytometry. Representative histograms are shown in a and percentages of $\mathrm{CD}_{2} 5^{+} \mathrm{Foxp}^{+}$cells among CD4-gated lymphocytes are expressed as mean \pm s.e.m. $\left({ }^{\star} P<0.05,{ }^{* \star} P<0.01, n=6 /\right.$ group) (b). (c) Total Inflammatory scores are represented as mean \pm s.e.m. $\left({ }^{\star} P \leq 0.05, n=8-14 /\right.$ group). (d) Ten-week-old GDX-SAMP mice were implanted with subcutaneous estrogen for 6 weeks (see Materials and Methods). Total inflammatory scores following 6 weeks of indicated hormone treatment (expressed as mean \pm s.e.m., ${ }^{*} P<0.05, n=6 /$ group).

(Figures 3 and 4). We initially asked whether E2 can directly affect the suppressive capacity of Tregs by adding exogenous E2 (10 nм) to in vitro $\mathrm{T}$-cell suppression assays. Interestingly, we found that the suppressive function of Tregs from both SAMP-M and -F mice were unchanged by the addition of E2 or the ER agonists PPT and DPN (10 nM, data not shown).

As E2 did not appear to change the suppressive capacity of Tregs, we asked whether E2 mediates immunosuppressive effects through direct signaling to naive T cells. We cultured $\mathrm{CD} 4{ }^{+} \mathrm{CD} 25^{-}$Tconvs with E2, PPT, or DPN (10 nM) for 3 days in CFSE proliferation assays. We found that the percentage of dividing cells (reduced CFSE) was significantly lower in SAMP$\mathrm{M}$ cultures compared with SAMP-F cultures ( $44.4 \pm 1.2 \%$ vs. $54.7 \pm 1.8 \%$, respectively) with the addition of E2 (Figure 6a), suggesting that SAMP-M T cells are more susceptible to E2mediated immunosuppression. When the proliferation of E2stimulated $\mathrm{T}$ cells was calculated with respect to that of unstimulated $\mathrm{T}$ cells from matched donors, both E2 and DPN treatment resulted in a significant reduction in the proliferation of SAMP-M T cells compared with SAMP-F T cells (Figure 6b). Collectively, these data suggest that SAMP-F T cells are not as responsive to regulation by E2 signaling as SAMP-M T cells, likely contributing to their heightened activation in vivo. Further, the heightened activation status of these cells may partially explain the observed Treg dysfunction in female vs. male SAMP mice.

\section{DISCUSSION}

Immunological, epidemiological, and clinical evidence indicates that female sex hormones and susceptibility genes on the $\mathrm{X}$ chromosome are capable of inducing differences in the etiology and pathophysiology of chronic immune/inflammatory diseases. ${ }^{32}$ In $\mathrm{IBD}$, specifically $\mathrm{CD}$, emerging evidence supports clear gender disparity, particularly in disease severity; however, the mechanism(s) of sex differences in the pathogenesis of chronic intestinal inflammation remain poorly understood. Specifically, female patients often experience dichotomous alterations in symptoms during changes in hormonal levels, such as puberty, pregnancy, and menopause. This correlation strongly suggests a role for hormones in modulating disease, yet these mechanisms have not been fully studied.

The present study reveals that the SAMP model of CD-like ileitis recapitulates several aspects of human $\mathrm{CD}$, including an accelerated and more severe disease course in female patients. Interestingly, genetic outcross studies and linkage analysis of SAMP mice have identified loci on several chromosomes with polymorphic markers that segregate with the ileitis phenotype, including X-linked susceptibility loci. ${ }^{33}$ SAMP therefore represents a unique tool to examine cellular and molecular mechanisms underlying gender bias in IBD. Our study reveals several novel observations regarding the interplay of hormone signaling and $\mathrm{T}$-cell function in the context of mucosal inflammation that begin to unravel the mechanisms behind gender differences in autoimmunity.

Our results show that SAMP-F mice display a dense infiltrate of leukocytes in the inflamed ileum beginning at approximately 6 weeks of age, corresponding to the onset of puberty (Figure 1b). Infiltrating cells drain to the MLN and comprise a heterogeneous population of lymphocytes and myeloid cells, including Tregs. The nTreg population in mice generally comprises $5-10 \%$ of $\mathrm{CD} 4^{+}$cells, and the majority of 
a

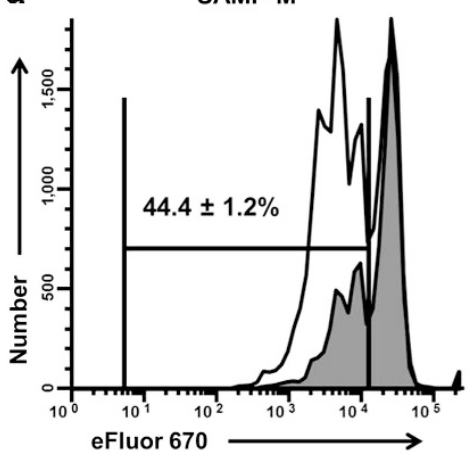

SAMP-F

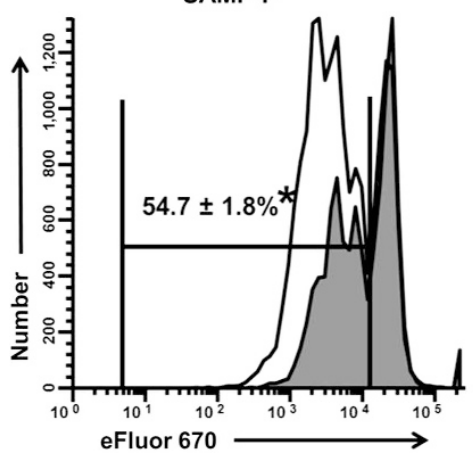

b

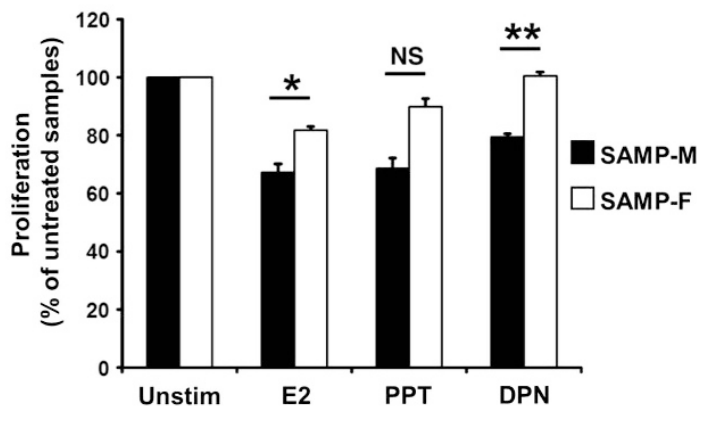

Figure 6 SAMP-F Tregs are resistant to E2-mediated immunosuppression. (a, b) CD $^{+}$CD2 $^{-} 5^{-}$Tconvs were isolated from $10-$ week-old SAMP mice by FACS. Sorted cells were labeled with eFluor 670 cell proliferation dye and cultured in vitro with $\alpha$ CD3/ $\alpha$ CD28 in the presence or absence of E2, PPT, or DPN (10 nM) for 3 days. Proliferation was assessed by e670 dye dilution. (a) Representative histograms show the proliferation of viable, CD4-gated cells in the absence (white peaks) and presence (gray peaks) of E2. Cumulative statistics show the percentage of dividing cells in the presence of E2 ( ${ }^{\star} P<0.002, n=3$ /group). (b) Percent proliferation of E2-, PPT-, or DPN-treated cells was calculated relative to percent proliferation of untreated cells using dye dilution and gating strategy shown in a. Results are expressed as mean \pm s.e.m. ( $P<0.001, n=3 /$ group).

$\mathrm{CD} 4{ }^{+} \mathrm{CD} 25^{+}$cells co-express Foxp3. ${ }^{34}$ Interestingly, our results indicate that fewer than $50 \%$ of the $\mathrm{CD} 4{ }^{+} \mathrm{CD} 25^{+}$cells from MLNs of SAMP-F mice express Foxp3, compared with the majority of $\mathrm{CD}^{+}{ }^{+} \mathrm{CD} 25^{+}$cells expressing Foxp3 in SAMP-M and AKR control mice (Figure 2). Loss of Foxp3 expression in mature Tregs has been reported to attenuate Treg suppressive functions and is associated with autoimmune disease; ${ }^{35}$ of particular relevance to GALT-resident $\mathrm{T}$ cells, the adjuvant nature of commensal flora has been reported to drive phenotypic conversion of $\mathrm{T}$ cells and to divert them away from regulatory lineages. ${ }^{36}$ Whether $\mathrm{CD} 4{ }^{+} \mathrm{CD} 25^{+}$Foxp $3^{\text {low }}$ lymphocytes retain suppressive function in vivo is unknown, as Foxp3-GFP or -RFP reporter mice do not exist on the SAMP background; however, future backcrossing of these Foxp3 reporter mice onto SAMP may address this question. Given the importance of bacterial flora to mucosal immune outcomes, it is also intriguing that there appears to be gender-associated differences in the composition of the intestinal microbiome itself, such that a predominance of different species may alter innate or adaptive immune cell function. ${ }^{37}$

Homeostasis between regulatory and effector T-cell populations is a key determinant of the in vivo balance between selftolerance and autoimmunity. Using an in vivo adoptive transfer model, previous studies have shown that GALT-derived Tregs from SAMP mice are functionally impaired. ${ }^{17}$ Our current work builds upon that observation to show that CD $4{ }^{+} \mathrm{CD} 25^{+}$ Tregs isolated from SAMP-F mice show increased functional impairment, both in vivo and in vitro, compared with Tregs from SAMP-M mice (Figure 3). This finding is in agreement with previous work showing phenotypic and functional defects in Tregs from female autoimmune patients, ${ }^{38}$ as well as from female rodents in experimental models of autoimmunity. ${ }^{39,40}$ Notably, a strength of the CD45RB ${ }^{\text {high }}$ adoptive transfer model is that it is designed to test the suppressive function of Tregs on the same population of pathogenic Teff cells isolated from MLNs of SAMP-M mice. This eliminates potential variation in effector cell proliferation, and thus allows us to infer that differences in in vivo suppression are derived from inherent differences in Treg suppressive function, rather than differences in Teff proliferation.

Our CD45RB ${ }^{\text {high }}$ adoptive transfer experiments also demonstrate that Tregs derived from SAMP-F mice are less effective than those from SAMP-M mice in downregulating proinflammatory cytokine production in the gut (Supplementary Figure S3). Protein expression of both Th1- and Th2associated cytokines was significantly higher in mice receiving co-transfer of SAMP-F Tregs, compared with those receiving SAMP-M Tregs. Interestingly, IL-17A and IL-22 expression were also dampened by the co-transfer of SAMP-M, but not -F, Tregs, suggesting that CD45RB ${ }^{\text {low }}$ GALTderived Tregs maintain the capacity to suppress Th 17 responses in SAMP-M mice.

Given that female mice exhibit accelerated ileitis, we sought to determine whether estrogen signaling has a mechanistic role in this process by examining the relative contribution of signaling through the two E2 receptor isoforms. Signaling through both $\mathrm{ER} \alpha$ and $\mathrm{ER} \beta$ is able to downregulate ileal inflammation in vivo when administered continuously for 6 weeks to GDX mice, beginning at 10 weeks of age (Figure 5c). However, isoform-specific effects on T-cell differentiation and function suggest that the in vivo mechanism of action for estrogen is multi-factorial.

Both Tconvs and Tregs express ER isoforms $\mathrm{ER} \alpha$ and $\mathrm{ER} \beta$ (Figure 4a and b). However, our findings suggest that signaling through these receptors leads to distinct immune outcomes depending on the phenotype of the T cell. Specifically, signaling through $\mathrm{ER} \beta$, but not $\mathrm{ER} \alpha$, reinforces Treg phenotype and function by enhancing expression of Foxp3 in CD $4{ }^{+} \mathrm{CD} 25^{+}$ Tregs, as well as secretion of IL-10 and TGF $\beta$ by these cells (Figure 4d). Fully differentiated Tregs do not similarly respond to $\mathrm{ER} \alpha$ signaling (Figure $\mathbf{4 d}$ ). Tconvs, conversely, respond to both $\mathrm{ER} \alpha$ and $\mathrm{ER} \beta$ signaling by downregulation of proliferation in response to $\alpha \mathrm{CD} 3 / \alpha \mathrm{CD} 28$ (Figure 6). Tconvs also upregulate expression of Treg-associated markers, including Foxp3, Helios, PD1, CTLA4, and LAG3 in response to E2 or ER agonists (Figure $\mathbf{4 c}$ ). E2 has been previously reported to 
upregulate PD1 on Treg, leading to enhanced suppression; ${ }^{41}$ this is likely an important mechanism for E2's immunosuppressive action. Collectively, our data suggests that $\mathrm{E} 2$ signals to both ER isoforms on naive T cells, diverting them away from pathogenic effector cells and toward tolerogenic inducible Tregs (iTregs) through induction of Treg-associated genes. ${ }^{29,41}$ Interestingly, whereas naïve $\mathrm{T}$ cells respond to $\mathrm{E} 2$ through both ER isoforms, mature Tregs respond preferentially through ER $\beta$ signaling. Functional outcomes of this signaling include enhanced expression of Foxp3, IL-10, and TGF $\beta$ (Figure 4d).

Moreover, and in agreement with previous work suggesting an immunosuppressive function for E2, ${ }^{42,43}$ in vivo administration of DPN significantly increases the percentage of GALT-derived $\mathrm{CD}^{+}{ }^{+} \mathrm{CD} 25^{+} \mathrm{Foxp}^{+}$Tregs (Figure 5a and b). PPT signaling through ER $\alpha$ shows an inability to expand the mucosal Treg population, and in fact, Treg frequency is reduced in PPT-treated animals compared with those receiving E2 (Figure 5a).

Among its beneficial effects, signaling through ER $\beta$ has previously been shown to maintain intestinal barrier function. ${ }^{44}$ Although SAMP mice display a permeability defect compared with AKR controls at an early age, we found no differences in permeability between SAMP-M and -F mice (Supplementary Figure S6A), suggesting that the SAMP permeability defect does not influence gender-related pathologies, including accelerated disease course or changes to Treg function. We also examined intestinal permeability following in vivo E2/PPT/DPN administration to GDX-SAMP mice, and found that none of the E2 ligands resulted in a loss of permeability (Supplementary Figure S6B). In fact, treatment with ER $\beta$-specific DPN resulted in a modest yet statistically significant increase in permeability, suggesting that the beneficial effects of ER $\beta$ signaling are likely due to direct effects on immune cells rather than to changes in permeability. Importantly, our results do not address the potential for ER $\beta$ to confer protection against permeability defects and/or gender bias in the SAMP model if administered prior to the onset of ileitis; this is an important area for future study, particularly in light of evidence that ER $\beta$ stimulation can promote proper intestinal barrier function. ${ }^{44}$

The present study describes possible mechanisms that contribute to gender disparity characteristic of both SAMP ileitis and patients with $\mathrm{CD}$. Our data suggest that estrogen signaling may confer immunoprotection through both ER $\alpha$ and ER $\beta$, operating in tandem mechanisms on conventional as well as regulatory $\mathrm{T}$ cells. Ultimately, E2 signaling in both isoforms enhances tolerance, via upregulation of Treg suppressive function, as well as induction of iTregs from Tconv precursors. These combined mechanisms confer some level of immunoprotection for SAMP-M mice through expansion of mucosal Tregs, whereas SAMP-F T cells are resistant to E2's beneficial effects. These findings, combined with the observation that SAMP-M mice specifically undergo ER $\beta$-mediated expansion of Tregs in vivo and IL-10/TGF $\beta$ production in vitro, support the concept that GALT-derived Tregs from SAMP-M mice are more functionally effective than SAMP-F mice at ameliorating chronic ileitis. Collectively, our data suggest that the development of therapeutics selectively designed to enhance immunoprotective ER signaling on T cells may hold promise in the treatment of chronic inflammatory disorders such as CD.

\section{METHODS}

Mice. SAMP, AKR/J, and $\mathrm{TNF}^{\triangle \mathrm{ARE} /+}$ mice were propagated at the University of Virginia (UVA) and Case Western Reserve University (CWRU), with SAMP founders provided by S. Matsumoto (Yakult Central Institute for Microbiological Research, Tokyo, Japan) ${ }^{45}$ and $\mathrm{TNF}^{\Delta \mathrm{ARE} /+}$ founders provided by G. Kollias (Biomedical Sciences Research Center "Alexander Fleming," Vari, Greece). ${ }^{27}$ Mice were bred and maintained under SPF conditions, fed standard laboratory chow (Harlan Teklad, Indianapolis, IN), and kept on a $12 \mathrm{~h}$ light/dark cycle. C3Smn.CB17-Prkdcscid/J (SCID) mice were purchased from The Jackson Laboratory (Bar Harbor, ME). All procedures were approved by the IACUC at UVA and CWRU.

Histologic evaluation of intestinal inflammation. Distal $10 \mathrm{~cm}$ of ilea or entire length of colon from experimental mice were removed, flushed of fecal contents, opened longitudinally, and placed in Bouin's fixative. Tissues were embedded in paraffin, cut to $3 \mu \mathrm{m}$, and stained with H\&E. Disease severity was evaluated by a trained pathologist (James R. Mize) in a blinded fashion using established histologic scoring systems for ileitis and colitis. ${ }^{46}$ Images were obtained on an Axiophot microscope, captured on an Axiocam and assembled using Axiovision Release 4.5 (Carl Zeiss, Thornwood, NY).

Flow cytometry. Cell suspensions were prepared from MLNs and spleens as previously described. ${ }^{46}$ One million $\left(10^{6}\right)$ cells/sample were stained with the following antibody combinations: Alexa-488-, PE-, and APC-labeled rat anti-mouse CD4 (RM4-5), CD25 (PC61) (BD, BD Pharmingen, San Diego, CA), and Foxp3 (140D) (Biolegend, San Diego, CA). For intracellular staining, cells were fixed after cell surface staining, followed by permeabilization and staining for Foxp3 according to manufacturer's instructions (Biolegend). Samples were analyzed with a FACSCalibur flow cytometer and CellQuest Software (both Becton Dickinson, San Jose, CA).

Colitis adoptive transfer model. MLN CD4 ${ }^{+}$cells were negatively selected by magnetic beads (Miltenyi Biotec, Auburn, CA) and stained with anti-CD4 and anti-CD45RB antibodies (BD). FACS-sorted $\mathrm{CD} 4{ }^{+} \mathrm{CD}_{45 \mathrm{RB}^{\text {hi }}}\left(3-5 \times 10^{5}\right)$ and $\mathrm{CD} 4{ }^{+} \mathrm{CD} 45 \mathrm{RB}^{\text {low }}\left(10^{5}\right)$ cells were transferred i.p. into 6-week-old MHC-matched SCID mice. CD45RB ${ }^{\text {hi }}$ and $\mathrm{CD} 45 \mathrm{RB}^{\text {low }}$ were defined as the top- and bottom- $30 \%$ of CD45RB-expressing cells within the $\mathrm{CD} 4{ }^{+}$lymphocyte gate. Eight weeks post transfer, mice were sacrificed and colons processed for histologic evaluation. ${ }^{26}$ MLN cells were collected for in vitro stimulation assays and cytokine production as described above.

In vitro T-cell proliferation and suppression assays. FACS-purified $\mathrm{CD} 4{ }^{+} \mathrm{CD} 25^{-}$Tconvs and $\mathrm{CD} 4{ }^{+} \mathrm{CD} 25^{+}$Tregs were isolated from 10 -week-old mice. Tconvs were labeled with eFluor 670 (CFSE analog, $0.5 \mu \mathrm{M})$ and cultured with or without a 1:1 ratio of Tregs. $\alpha$-CD3 $\left(1 \mu \mathrm{g} / \mathrm{ml}^{-1}\right)$ and $\alpha$-CD28 $\left(1 \mu \mathrm{g} \mathrm{ml}^{-1}\right)$-coated beads (Miltenyi Biotec) were added to cultures at 1:4 bead:Tconv ratio. Proliferation was determined after 3 days of culture by flow cytometric dye dilution assay.

Immunoblots. Western blots for ER $\alpha$, ER $\beta$, and Lamin-B1 were performed using nuclear extracts (Pierce NE-PER nuclear extraction kit, Thermo Scientific, Rockford, IL) of FACS-sorted Tconvs and Tregs. Lysates were immunoblotted as previously described ${ }^{47}$ using polyclonal Abs specific for ER $\alpha$ (Santa Cruz Biotechnology, Santa Cruz, CA), ER $\beta$ (Santa Cruz Biotechnology), and Lamin-B1 (Cell Signaling Technology, Danvers, MA), followed by goat anti-rabbit 
HRP (Santa Cruz Biotechnology). Chemiluminescent signals were developed using SuperSignal West Substrate (Thermo Scientific) and detected on Kodak BioMax MR film (Kodak, Rochester, NY). Densitometry was performed using a VersaDoc imaging system and QuantityOne software (both BioRad, Hercules, CA) comparing mean adjusted volume. Western blots for Foxp3 were performed using total cell lysates probed with primary Ab specific for Foxp3 (Santa Cruz Biotechnology), followed by goat anti-mouse HRP (EMD Millipore, Billerica, MA).

RNA extraction and quantitative PCR analysis. FACS-purified $\mathrm{CD} 4{ }^{+} \mathrm{CD} 25^{-}$Tconvs from 10 -week-old mice were treated ex vivo with vehicle (Ctrl), E2, PPT, or DPN (all Tocris Bioscience, Ellisville, $\mathrm{MO}$, used at $10 \mathrm{~nm}$ ) for $2 \mathrm{~h}$. Total RNA was isolated from cultured cells using the High Pure RNA Isolation Kit (Roche Applied Science, Indianapolis, IN) as described by the manufacturer. Total RNA ( $1 \mu \mathrm{g})$ was reverse transcribed using reverse transcriptase. The resulting cDNA was diluted to $100 \mu \mathrm{l}$ and used in subsequent real-time PCR reactions. Gene expression was assessed using the Taqman system from Applied Biosystems (Life Technologies, Carlsbad, CA).

In vitro cell stimulation assays. Cell suspensions were prepared from MLNs and spleens as previously described. ${ }^{46}$ MACS-enriched $\mathrm{CD} 4{ }^{+} \mathrm{CD} 25^{+} \mathrm{T}$ cells $\left(\mathrm{CD} 4{ }^{+} \mathrm{CD} 25^{+}\right.$T regulatory $\mathrm{T}$-cell isolation kit; Miltenyi Biotec), were cultured in 96 -well plates coated with $\alpha$-mouse CD3 $\left(1 \mu \mathrm{g} \mathrm{ml}^{-1}\right.$, clone $\left.145-2 \mathrm{C} 11\right)$ and soluble $\alpha$-CD28 $\left(0.5 \mu \mathrm{g} \mathrm{ml}^{-1}\right.$, clone 37.51) (both BD Bioscience). PPT and DPN were added at $10 \mathrm{~nm}$ (Tocris Bioscience).

Hormone/ER agonist treatment and estrogen detection. Hormones (Sigma, St Louis, MO) were continuously delivered to 10 -week-old GDX SAMP for 6 weeks by s.c. placement of E2-filled hormone implants ( $1 \mathrm{~cm}$ length) prepared in Silastic tubing $(5 \mathrm{~mm}, 1.02 \mathrm{~mm}$ ID $\times 2.16 \mathrm{~mm}$ OD) as described previously; ${ }^{48}$ empty implant (blank) served as Ctrl. PPT, DPN (both $10 \mathrm{mg} \mathrm{kg}^{-1}$, i.p.), E2 $\left(10 \mu \mathrm{g} \mathrm{kg}^{-1}\right.$, i.p.), or vehicle Ctrl (DMSO:PBS, vol/vol) was delivered by daily $200 \mu \mathrm{l}$ injections for 6 weeks. Serum estrogen levels were detected using an estradiol estimation kit (Alpco Diagnostics, Salem, NH).

Cytokine protein measurements. IL-6, IL-12, TNF $\alpha$, IFN $\gamma$, IL-2, and IL-4 were measured from activated MLN cell supernatants by cytokine array (protein $\sim$ Q-Plex Mouse Cytokine-Screen IR 16-Plex kit, Quansys Biosciences, Logan, UT). IL-10, TGF $\beta$, IL-17A, and IL-22 were detected by ELISA (eBioscience, San Diego, CA) according to manufacturer's instructions. Colon samples from adoptive transfer experiments were processed and assayed for myeloperoxidase activity as previously described. ${ }^{49}$

Permeability assays. Intestinal epithelial permeability to solutes was measured using urinary fractional excretion ratio of lactulose to mannitol (Lac/Man excretion ratio), as previously described. ${ }^{50}$

Statistical analysis. Two-tailed Student's $t$-test with Welch's correction and Bonferroni's test were performed using GraphPad Prism 5 (GraphPad Software, La Jolla, CA). $P$-values $\leq 0.05$ were considered significant.

Supplementary Material is linked to the online version of the paper at http://www.nature.com/mi

\section{ACKNOWLEDGMENTS}

We would like to thank R. Michael Sramkoski, Muhammadreza Sachedina, Michael Whitecar, Mary Riggins, Jonathan "Adam" Alford, Jason D'Antuono, William Ross, Sharon Hoang, and James "Rusty" Mize, and for their technical support and expertise. We also acknowledge continued support from the National Institutes of Health: Al102269, DK091222, and DK056762 (TTP); DK083251 NRSA T32 (WAG); and a Research Fellowship Award from the Crohn's \& Colitis Foundation of America (RRG).

\section{DISCLOSURE}

The authors declared no conflict of interests.

c 2014 Society for Mucosal Immunology

\section{REFERENCES}

1. Jacobson, D.L., Gange, S.J., Rose, N.R. \& Graham, N.M. Epidemiology and estimated population burden of selected autoimmune diseases in the United States. Clin. Immunol. Immunopathol. 84, 223-243 (1997).

2. Whitacre, C.C., Reingold, S.C. \& O'Looney, P.A. A gender gap in autoimmunity. Science 283, 1277-1278 (1999).

3. Whitacre, C.C. Sex differences in autoimmune disease. Nat. Immunol. 2, 777-780 (2001).

4. Hanauer, S.B. Inflammatory bowel disease: epidemiology, pathogenesis, and therapeutic opportunities. Inflamm. Bowel Dis. 12 (Suppl 1), S3-S9 (2006).

5. Montgomery, S.M., Wakefield, A.J. \& Ekbom, A. Sex-specific risks for pediatric onset among patients with Crohn's disease. Clin. Gastroenterol. Hepatol. 1, 303-309 (2003).

6. Saibeni, S. et al. Gender and disease activity influence health-related quality of life in inflammatory bowel diseases. Hepatogastroenterology $\mathbf{5 2}$, 509-515 (2005).

7. Mogadam, M, Korelitz, B.I., Ahmed, S.W., Dobbins, W.O. 3rd \& Baiocco, P.J. The course of inflammatory bowel disease during pregnancy and postpartum. Am. J. Gastroenterol. 75, 265-269 (1981).

8. Fish, E.N. The X-files in immunity: sex-based differences predispose immune responses. Nat. Rev. Immunol. 8, 737-744 (2008).

9. Saruta, M, Targan, S.R., Mei, L, Ippoliti, A.F., Taylor, K.D. \& Rotter, J.I. High-frequency haplotypes in the $X$ chromosome locus TLR8 are associated with both CD and UC in females. Inflamm. Bowel Dis. 15, 321-327 (2009).

10. Nguyen, D.D. et al. Wiskott-Aldrich syndrome protein deficiency in innate immune cells leads to mucosal immune dysregulation and colitis in mice. Gastroenterology 143, 719-729 e711-712 (2012).

11. Duncan, G.S. et al. 2-Methoxyestradiol inhibits experimental autoimmune encephalomyelitis through suppression of immune cell activation. Proc. Natl Acad. Sci. US A 109, 21034-21039 (2012).

12. Wu, W.F., Tan, X.J., Dai, Y.B., Krishnan, V, Warner, M. \& Gustafsson, J.A. Targeting estrogen receptor beta in microglia and $T$ cells to treat experimental autoimmune encephalomyelitis. Proc. Natl Acad. Sci. USA 110, 3543-3548 (2013).

13. Harnish, D.C. et al. Beneficial effects of estrogen treatment in the HLA-B27 transgenic rat model of inflammatory bowel disease. Am. J. Physiol. Gastrointest. Liver Physiol. 286, G118-G125 (2004).

14. Verdu, E.F., Deng, Y, Bercik, P \& Collins, S.M. Modulatory effects of estrogen in two murine models of experimental colitis. Am. J. Physiol. Gastrointest. Liver Physiol. 283, G27-G36 (2002).

15. Bjornstrom, L \& Sjoberg, M. Mechanisms of estrogen receptor signaling: convergence of genomic and nongenomic actions on target genes. Mol. Endocrinol. 19, 833-842 (2005).

16. Cunningham, M. \& Gilkeson, G. Estrogen receptors in immunity and autoimmunity. Clin. Rev. Allergy Immunol. 40, 66-73 (2011).

17. Ishikawa, D. et al. Tregs are dysfunctional in vivo in a spontaneous murine model of Crohn's disease. Mucosal Immunol. 6, 267-275 (2013).

18. Sakaguchi, S. et al. Foxp3 + CD25 + CD4 + natural regulatory T cells in dominant self-tolerance and autoimmune disease. Immunol. Rev. 212, 8-27 (2006).

19. Shevach, E.M. Mechanisms of foxp $3+T$ regulatory cell-mediated suppression. Immunity 30, 636-645 (2009).

20. Himmel, M.E., Hardenberg, G, Piccirillo, C.A., Steiner, T.S. \& Levings, M.K. The role of T-regulatory cells and Toll-like receptors in the pathogenesis of human inflammatory bowel disease. Immunology 125, 145-153 (2008).

21. Izcue, A, Coombes, J.L. \& Powrie, F. Regulatory lymphocytes and intestinal inflammation. Ann. Rev. Immunol. 27, 313-338 (2009).

22. Maul, J. et al. Peripheral and intestinal regulatory CD4 + CD25(high) T cells in inflammatory bowel disease. Gastroenterology 128, 1868-1878 (2005).

23. Powrie, F, Leach, M.W., Mauze, S, Caddle, L.B. \& Coffman, R.L. Phenotypically distinct subsets of CD4 $+\mathrm{T}$ cells induce or protect from 
chronic intestinal inflammation in C. B-17 scid mice. Int. Immunol. 5, 1461 1471 (1993).

24. Nagler-Anderson, C, Bhan, A.K., Podolsky, D.K. \& Terhorst, C. Control freaks: immune regulatory cells. Nat. Immunol. 5, 119-122 (2004).

25. Pizarro, T.T. et al. SAMP1/YitFc mouse strain: a spontaneous model of Crohn's disease-like ileitis. Inflamm. Bowel Dis. 17, 2566-2584 (2011).

26. Olson, T.S. et al. Expanded B cell population blocks regulatory T cells and exacerbates ileitis in a murine model of Crohn disease. J. Clin. Invest. 114, 389-398 (2004).

27. Kontoyiannis, D, Pasparakis, M, Pizarro, T.T., Cominelli, F. \& Kollias, G. Impaired on/off regulation of TNF biosynthesis in mice lacking TNFAU-rich elements: implications for joint and gut-associated immunopathologies. Immunity 10, 387-398 (1999).

28. Miyara, M. et al. Functional delineation and differentiation dynamics of human $\mathrm{CD} 4+$ T cells expressing the FoxP3 transcription factor. Immunity 30, 899-911 (2009).

29. Tai, P. et al. Induction of regulatory T cells by physiological level estrogen. J. Cell Physiol. 214, 456-464 (2008).

30. Campbell-Thompson, M, Lynch, I.J. \& Bhardwaj, B. Expression of estrogen receptor (ER) subtypes and ERbeta isoforms in colon cancer. Cancer Res. 61, 632-640 (2001).

31. Kudwa, A.E., Harada, N, Honda, S.I. \& Rissman, E.F. Effects of organisational oestradiol on adult immunoreactive oestrogen receptors (alpha and beta) in the male mouse brain. J. Neuroendocrinol. 19, 767-772 (2007).

32. Smith-Bouvier, D.L. et al. A role for sex chromosome complement in the female bias in autoimmune disease. J. Exp. Med. 205, 1099-1108 (2008).

33. Kozaiwa, K. et al. Identification of a quantitative trait locus for ileitis in a spontaneous mouse model of Crohn's disease: SAMP1/YitFc. Gastroenterology 125, 477-490 (2003).

34. Fontenot, J.D., Gavin, M.A. \& Rudensky, A.Y. Foxp3 programs the development and function of $\mathrm{CD} 4+\mathrm{CD} 25+$ regulatory $\mathrm{T}$ cells. Nat. Immunol. 4, 330-336 (2003).

35. Wan, Y.Y. \& Flavell, R.A. Regulatory T-cell functions are subverted and converted owing to attenuated Foxp3 expression. Nature 445, 766-770 (2007).

36. Hall, J.A. et al. Commensal DNA limits regulatory T cell conversion and is a natural adjuvant of intestinal immune responses. Immunity $\mathbf{2 9}$ 637-649 (2008).

37. Markle, J.G. et al. Sex differences in the gut microbiome drive hormonedependent regulation of autoimmunity. Science 339, 1084-1088 (2013).
38. Barreto, M. et al. Low frequency of CD4 + CD25 + Treg in SLE patients: a heritable trait associated with CTLA4 and TGFbeta gene variants. BMC Immunol. 10, 5 (2009).

39. Lapierre, P, Beland, K, Martin, C, Alvarez, F Jr. \& Alvarez, F. Forkhead box p3 + regulatory $T$ cell underlies male resistance to experimental type 2 autoimmune hepatitis. Hepatology 51, 1789-1798 (2010).

40. Pop, S.M., Wong, C.P., Culton, D.A., Clarke, S.H. \& Tisch, R. Single cell analysis shows decreasing FoxP3 and TGFbeta1 coexpressing CD4+ CD25 + regulatory T cells during autoimmune diabetes. J. Exp. Med. 201, 1333-1346 (2005).

41. Polanczyk, M.J., Hopke, C, Vandenbark, A.A. \& Offner, H. Treg suppressive activity involves estrogen-dependent expression of programmed death-1 (PD-1). Int. Immunol. 19, 337-343 (2007).

42. Polanczyk, M.J. et al. Cutting edge: estrogen drives expansion of the CD4 + CD25 + regulatory T cell compartment. J. Immunol. 173, 2227-2230 (2004).

43. Prieto, G.A. \& Rosenstein, Y. Oestradiol potentiates the suppressive function of human CD4 CD25 regulatory T cells by promoting their proliferation. Immunology 118, 58-65 (2006).

44. Looijer-van Langen, M, Hotte, N, Dieleman, L.A., Albert, E, Mulder, C \& Madsen, K.L. Estrogen receptor-beta signaling modulates epithelial barrier function. Am. J. Physiol. Gastrointest. Liver Physiol. 300, G621-G626 (2011).

45. Matsumoto, S. et al. Inflammatory bowel disease-like enteritis and caecitis in a senescence accelerated mouse P1/Yit strain. Gut 43, 71-78 (1998).

46. Bamias, G. et al. Commensal bacteria exacerbate intestinal inflammation but are not essential for the development of murine ileitis. J. Immunol. 178, 1809-1818 (2007).

47. Goodman, W.A., Young, A.B., McCormick, T.S., Cooper, K.D. \& Levine, A.D. Stat3 phosphorylation mediates resistance of primary human Tcells to regulatory Tcell suppression. J. Immunol. 186, 3336-3345 (2011).

48. Bodo, C. \& Rissman, E.F. The androgen receptor is selectively involved in organization of sexually dimorphic social behaviors in mice. Endocrinology 149, 4142-4150 (2008).

49. Boughton-Smith, N.K., Wallace, J.L. \& Whittle, B.J. Relationship between arachidonic acid metabolism, myeloperoxidase activity and leukocyte infiltration in a rat model of inflammatory bowel disease. Agents Actions $\mathbf{2 5}$, 115-123 (1988).

50. Olson, T.S. et al. The primary defect in experimental ileitis originates from a nonhematopoietic source. J. Exp. Med. 203, 541-552 (2006). 